\title{
ASSOCIATION OF PATIENT RELATED RISKFACTORS WITH EFFECTIVENESS OF PALLIATIVE CHEMOTHERAPY IN CANCER PATIENTS
}

\author{
VINODKUMAR MUGADA, POLARAMSETTI SNEHA PRIYANKA, PIDAPARTHY PRASHANTH, PEDASANAGANTI \\ JYOTHIRMAI
}

Department of Pharmacy Practice, Aditya Pharmacy College, ADB Road, Surampalem, East Godavari Dist., A. P-533437

Email: mugadavinodkumar18@gmail.com

Received: 30 Jun 2017 Revised and Accepted: 31 Aug 2017

ABSTRACT

Objective: To assess the association of some risk factors on the effectiveness of palliative chemotherapy treatment in cancer patients.

Methods: A prospective observational study was conducted in the department of radiotherapy for a period of 6 mo. Ages, Gender, Cancer type, Physical Functioning, Anxiety and Depression, Medical Social Support, Comorbidities, Adverse Drug Reactions are defined as risk factors. The effectiveness of palliative chemotherapy treatment was defined according to Response Evaluation Criteria in Solid Tumors (RECIST). Mean and standard deviation was calculated from the age. The association between risk factors and the effectiveness of chemotherapy treatment was found by chi-square test. The level of significance was taken as $\mathrm{p}<0.05$.

Results: The association between risk factors and effectiveness of palliative chemotherapy treatment was found using Chi-Square test. The mean age of patients in the present study was $50.57 \pm 12.62 \mathrm{y}$. Females were more commonly affected. The Majority of the patients were illiterate, married and homemaker. Reproductive system related cancers (50.66\%) were more predominant in the present study. A statistically significant association was observed between age $(\mathrm{p}=0.027)$, physical functioning $(\mathrm{p}=0.0076)$, anxiety $(\mathrm{p}=0.000072)$ and depression ( $\mathrm{p}=0.000016)$, co-morbidities $(\mathrm{p}<0.00001)$ and adverse drug reactions $(\mathrm{p}<0.00001)$ with effectiveness of chemotherapy treatment.

Conclusion: By predicting these risk factors prior to the initiation of treatment, we can minimize their unfavourable effect on the effectiveness of treatment.

Keywords: Risk factors, Chemotherapy, Adverse drug reactions, Response evaluation criteria in solid tumours

(C) 2017 The Authors. Published by Innovare Academic Sciences Pvt Ltd. This is an open access article under the CC BY license (http://creativecommons.org/licenses/by/4.0/) DOI: http://dx.doi.org/10.22159/ijpps.2017v9i10.21037

\section{INTRODUCTION}

Cancer is a complex diseases (200 different types) in which cells in a specific tissue do not completely respond to signals which regulate cellular differentiation, survival, proliferation and death, which leads to cell accumulation within the tissue, causing local damage and inflammation [1]. Roeland and Leblanc defined palliative chemotherapy as given in the non-curative setting to optimize symptom control, improve quality of life (QoL) and ideally, to improve survival [2]. These goals of the palliative chemotherapy can be met when the risk factors are monitored and when the pertinent management approaches are followed. Risk factors impede the therapeutic benefits of the therapy. Besides, they indirectly increase the disease progression in cancer patients. Therefore, our study aims to know the association of risk factors with the effectiveness of palliative chemotherapy in cancer patients.

The patient related risk factors that are studied are age, dependence of daily activities, comorbidities, anxiety and depression, social support. Barthel index was used to measure the patient's ability of performing daily activities independently and capability of patients to receive the palliative chemotherapy treatment. Patients with poor physical activity cannot withstand the chemotherapy. Comorbidities escalate the toxicity of chemotherapy treatment by physiological alteration of pharmacokinetic parameters of chemotherapy drugs. Chronic comorbidities such as heart and renal related diseases can influence the risk of febrile neutropenia which shows impact on patient's treatment outcome [3,4]. Cumulative Illness Rating Scale (CIRS) was used to measure the burden of comorbidities. Patients with anxiety and depression lack emotional and financial support from family. As a result, their adherence to treatment regimen will be poor and it leads to treatment failure. Hospital Anxiety and Depression Scale (HADS) was used to assess the anxiety and depression in cancer patients. Social support plays an important role in cancer patients because social support has a mediating role in the effect of adaptability style. If social support can reduce the effect of life's difficulty, stress and incidence of mood disorder, then cancer patients have improvement in chemotherapy treatment [5]. In addition, many studies indicate that more survival, better adaptability and mental health and higher quality of life are mostly seen in cancer patients receiving social support. Conversely, inadequate or unsatisfying social support leads to negative outcomes such as more stress and concern, more psychological and mental pressure and communication disorders, Poor emotional health, pessimistic attitude, hospitalization, poor survival [6, 7]. Medical Social Support Survey Scale (MSSSS) was used to measure the emotional and tangible support offered to cancer patients by their family members. The effectiveness of chemotherapy was assessed using Response Evaluation Criteria in Solid Tumors (RECIST).

The aim of the present study was to evaluate the association of Patient Related Risk factors with Effectiveness of Palliative Chemotherapy in Cancer Patients.

\section{MATERIALS AND METHODS}

\section{Study design and data collection}

This was a prospective cross sectional study conducted in the department of oncology of tertiary care teaching hospital, Kakinada for a period of 6 mo. The study was approved by Institutional ethical committee (APC/IEC/RT/18). All cancer patients of both gender, age $\geq 18 y e a r s$, diagnosed as having cancer and receiving only palliative chemotherapy as a mode of treatment were included in the study. Cancer patients who are critically ill, receiving other treatment modalities like radiation therapy along with palliative chemotherapy and relapsed cases were excluded from the study.

\section{Assessment}

Patient demographics like age, gender, educational level, marital status, employment status, household composition, cancer type, type of chemotherapy, adverse drug reactions etc. were collected in a specially designed data collection form. The Barthel index scale was 
used to determine the dependence of patient's daily activities and was scored as 100\%-Independence, 91-99-Slight Dependence, 6190-Moderate Dependence, 21-60-Severe Dependence, 0-20-Total Dependence. Cumulative Illness Rating Scale measures chronic medical illness burden while taking severity of the conditions into account. Hospital Anxiety and Depression Scale commonly used to determine the levels of anxiety and depression that a patient is experiencing

The Hospital Anxiety and Depression Scale is a fourteen item scale that generates ordinal data. Seven of the items relate to anxiety and seven relate to depression. Medical Social Support Survey scale was used to assess emotional and tangible support from patient family members. The above said scales were tabulated in a data collection form to make the final interpretation easier. Patient's response to chemotherapy for target and non-target lesions was determined by using Response Evaluation Criteria in Solid Tumors criteria. The response criteria were categorized as complete remission, partial remission, stable disease and progressive disease for both target lesions and non-target lesions.

\section{Statistical analysis}

Mean and standard deviation was calculated from the age. The association between risk factors and the effectiveness of chemotherapy treatment was found by chi-square test. The level of significance was taken as ${ }^{*} \mathrm{p}<0.05$

\section{RESULTS}

Table 1: Socio-demographic characteristics of chemotherapy patients $(\mathrm{N}=150)$

\begin{tabular}{|c|c|c|c|c|}
\hline S. No. & Patient demographics & Female & Male & Total \\
\hline \multirow[t]{5}{*}{1.} & Age & & & \\
\hline & $15-35$ & 16 & 5 & 21 \\
\hline & $36-55$ & 61 & 23 & 84 \\
\hline & $56-75$ & 21 & 21 & 42 \\
\hline & $76-95$ & 2 & 1 & 3 \\
\hline \multirow[t]{3}{*}{2.} & Gender & & & \\
\hline & Female & 100 & 0 & 100 \\
\hline & Male & 0 & 50 & 50 \\
\hline \multirow[t]{6}{*}{3.} & Cancer Type & & & \\
\hline & Reproductive System Related Cancer & 74 & 2 & 76 \\
\hline & Digestive System Related Cancer & 17 & 26 & 44 \\
\hline & Respiratory System & 2 & 8 & 10 \\
\hline & Nervous System & 0 & 2 & 2 \\
\hline & Others & 7 & 11 & 18 \\
\hline \multirow[t]{5}{*}{4.} & Educational Level & & & \\
\hline & Less Than High School & 19 & 3 & 22 \\
\hline & High School Graduate & 23 & 16 & 39 \\
\hline & Associate/Bachelor's Degree & 1 & 3 & 4 \\
\hline & Uneducated & 57 & 28 & 85 \\
\hline \multirow[t]{4}{*}{5.} & Marital Status & & & \\
\hline & Married & 75 & 48 & 123 \\
\hline & Widowed & 23 & 2 & 25 \\
\hline & Unmarried & 1 & 1 & 2 \\
\hline \multirow[t]{4}{*}{6.} & Employment Status & & & \\
\hline & Full Time Job & 20 & 37 & 57 \\
\hline & Unemployed & 0 & 12 & 12 \\
\hline & Homemaker & 81 & 0 & 81 \\
\hline \multirow[t]{6}{*}{7.} & Household Composition & & & \\
\hline & Lives With Partner & 5 & 2 & 7 \\
\hline & Lives Alone & 0 & 0 & 0 \\
\hline & Lives With Partner, Spouse Or Children & 70 & 46 & 116 \\
\hline & Lives With Children & 21 & 1 & 22 \\
\hline & Lives With Family Members & 3 & 2 & 5 \\
\hline
\end{tabular}

The mean age of patients in the present study $50.57 \pm 12.62 \mathrm{y}$. Females were more commonly affected. The Majority of the patients were illiterate, married and homemaker. Reproductive system related cancers $(50.66 \%)$ were more predominant in the present study. In the reproductive system related cancers, breast cancer was found to be more common (33.3\%).

Table 2: Daily activities of chemotherapy patients based on barthel index

\begin{tabular}{llll}
\hline S. No. & Scoring & Female & Male \\
\hline 1. & 100-Independence & 63 & 30 \\
2. & $91-99-$ Slight Dependence & 8 & 5 \\
3. & 61-90-Moderate Dependence & 25 & 13 \\
4. & 21-60-Severe Dependence & 3 & 39 \\
5. & 0-20-Total Dependence & 0 & 2 \\
6. & Total & 99 & 0 \\
\hline
\end{tabular}

The majority of the patients were independent $(62 \%)$ and can perform their daily activities on their own. A patient having a Barthel index score of 100 was considered as independent. So we can predict that patients were likely to be discharged to community living, i.e. Independent in transfers and able to walk or use wheelchair independently. Patients with score 100 i.e. independent were considered to be capable of receiving chemotherapy treatment 
Table 3: Co-morbidities of cancer patients based on cumulative Illness rating scale

\begin{tabular}{llll}
\hline S. No. & Co-Morbidities & Female & Male \\
\hline 1. & Hypertension & 1 & 1 \\
2. & Hypertension On Medication & 2 & 5 \\
3. & Diabetes Mellitus & 0 & 12 \\
4. & Diabetes Mellitus On Medication & 2 & 1 \\
5. & Surgery & 13 & 0 \\
6. & Head and Neck & 2 & 1 \\
7. & Liver Disease/Jaundice/Gall Stones & 2 & 15 \\
\hline
\end{tabular}

Table 4: Anxiety and depression of chemotherapy patients

\begin{tabular}{|c|c|c|c|c|}
\hline S. No. & Hospital anxiety and depression scale & Female & Male & Total \\
\hline 1. & Anxiety & & & \\
\hline 2. & Normal & 83 & 42 & 125 \\
\hline 3. & Borderline abnormal & 1 & 3 & 4 \\
\hline 4. & Abnormal & 15 & 6 & 21 \\
\hline 5. & Depression & & & \\
\hline 6. & Normal & 80 & 40 & 120 \\
\hline 7. & Borderline Abnormal & 3 & 3 & 6 \\
\hline 8. & Abnormal & 16 & 8 & 24 \\
\hline
\end{tabular}

Table 5: Emotional and tangible support to chemotherapy patients

\begin{tabular}{|c|c|c|c|c|}
\hline S. No. & Medical social support survey scale & Female & Male & Total \\
\hline 1. & $100.00 \%$ & 2 & 0 & 2 \\
\hline 2. & $81.20 \%$ & 85 & 45 & 130 \\
\hline 3. & $79.60 \%$ & 0 & 1 & 1 \\
\hline 4. & $64.00 \%$ & 2 & 2 & 4 \\
\hline 5. & $62.23 \%$ & 2 & 0 & 2 \\
\hline 6. & $57.81 \%$ & 0 & 2 & 2 \\
\hline 7. & $40.62 \%$ & 6 & 2 & 8 \\
\hline 8. & $29.68 \%$ & 1 & 0 & 1 \\
\hline
\end{tabular}

Table 6: Effectiveness of chemotherapy treatment (RECIST Criteria)

\begin{tabular}{llll}
\hline S. No. & RECIST criteria & Female & Male \\
\hline 1. & Complete Remission & 0 & 0 \\
2. & Partial Remission & 26 & 0 \\
3. & Stable Disease & 34 & 40 \\
4. & Progressive Disease & 37 & 20 \\
\hline
\end{tabular}

Table 7: Association between risk factors and effectiveness of chemotherapy treatment

\begin{tabular}{|c|c|c|c|c|c|c|}
\hline \multirow[t]{2}{*}{ S. No. } & \multirow[t]{2}{*}{ Risk factors } & \multicolumn{3}{|c|}{ RECIST criteria } & \multirow[t]{2}{*}{ Statistic } & \multirow[t]{2}{*}{ P-Value } \\
\hline & & PR & SD & PD & & \\
\hline \multirow[t]{5}{*}{1} & Age (In Years) & & & & & \\
\hline & $15-35$ & 4 & 6 & 10 & $\chi^{2}=$ & $\mathrm{p}=$ \\
\hline & $36-55$ & 28 & 28 & 26 & 14.2241 & $0.027231^{*}$ \\
\hline & $56-75$ & 5 & 19 & 21 & & \\
\hline & $76-95$ & 0 & 0 & 3 & & \\
\hline \multirow[t]{3}{*}{2} & Gender & & & & & \\
\hline & Female & 26 & 34 & 40 & $\chi^{2}=$ & $\mathrm{p}=$ \\
\hline & Male & 13 & 19 & 18 & 0.0724 & 0.964467 \\
\hline \multirow[t]{5}{*}{4} & Barthel Index & & & & & \\
\hline & Independence & 29 & 33 & 27 & $\chi^{2}=$ & $\mathrm{p}=$ \\
\hline & Slight Dependence & 2 & 8 & 3 & 17.472 & $0.007694^{*}$ \\
\hline & Moderate Dependence & 9 & 11 & 20 & & \\
\hline & Severe Dependence & 0 & 1 & 7 & & \\
\hline \multirow[t]{6}{*}{5} & Co morbidities & & & & & \\
\hline & Hypertension and HTN on Medication & 13 & 4 & 2 & $\chi^{2}=$ & $\mathrm{p}$ \\
\hline & Diabetes Mellitus and DM on Medication & 0 & 1 & 2 & 41.6832 & $<0.00001^{*}$ \\
\hline & Surgery & 13 & 0 & 1 & & \\
\hline & Head and Neck & 7 & 15 & 0 & & \\
\hline & Liver Disease/Jaundice/Gall Stones & 1 & 0 & 2 & & \\
\hline \multirow[t]{4}{*}{6} & Anxiety & & & & & \\
\hline & Normal & 38 & 48 & 39 & $\chi^{2}=$ & $\mathrm{p}=\mathbf{0 . 0 0 0 0 7 2 ^ { * }}$ \\
\hline & Borderline abnormal & 2 & 1 & 1 & 24.2136 & \\
\hline & Abnormal & 0 & 3 & 18 & & \\
\hline
\end{tabular}




\begin{tabular}{|c|c|c|c|c|c|c|}
\hline \multirow[t]{4}{*}{7} & Depression & & & & & \\
\hline & Normal & 37 & 46 & 35 & $\chi^{2}=$ & $\mathrm{p}=$ \\
\hline & Borderline Abnormal & 0 & 2 & 4 & 27.4174 & $0.000016^{*}$ \\
\hline & Abnormal & 0 & 5 & 21 & & \\
\hline \multirow[t]{9}{*}{8} & Medical Social Support Survey & & & & & \\
\hline & $100.00 \%$ & 1 & 0 & 1 & $\chi^{2}=$ & $\mathrm{p}=$ \\
\hline & $81.20 \%$ & 34 & 46 & 52 & 0.9409 & 0.918619 \\
\hline & $79.60 \%$ & 0 & 1 & 0 & & \\
\hline & $64.00 \%$ & 1 & 1 & 2 & & \\
\hline & $62.23 \%$ & 0 & 1 & 0 & & \\
\hline & $57.81 \%$ & 1 & 1 & 0 & & \\
\hline & $40.62 \%$ & 2 & 2 & 3 & & \\
\hline & $29.68 \%$ & 1 & 0 & 0 & & \\
\hline
\end{tabular}

$\left[\mathrm{PR}=\right.$ Partial remission, $\mathrm{SD}=$ Stable disease, $\mathrm{PD}=$ Progressive disease, ${ }^{*} \mathrm{p}$ value $<0.05$ was statistically significant $]$.

\section{DISCUSSION}

Statistically significant relationship was observed between age $(\mathrm{p}=0.027)$, physical functioning $(\mathrm{p}=0.0076)$, anxiety $(\mathrm{p}=0.000072)$ and depression $(\mathrm{p}=0.000016)$, co-morbidities $(\mathrm{p}<0.00001)$ and adverse drug reactions $(\mathrm{p}<0.00001)$.

Usually age of the cancer patient has an inverse relationship with the effectiveness of chemotherapy treatment. As the age of the patient increases, the physiological functioning decreases, this in turn affects the pharmacokinetic pattern of drugs and thus pharmacodynamics too. The tolerance to side effects to drugs will also decrease which in turn increases the frequency of adverse drug reactions. Indeed, this intolerability due to adverse drug reactions will delay the treatment, dose adjustments and sometimes cessation of treatment. Eventually, this leads to progression of disease.

Physical functioning was found to be a risk factor for effectiveness of chemotherapy treatment because, age, gender, chronic health conditions (co-morbidity), stage of cancer, site of cancer changes the physical functioning of cancer patient which leads to delay in chemotherapy treatment. Chronic health conditions, depressive symptomatology moderate the effect of intervention on physical function [8].

Co-morbidity is defined as the "coexistence of disorders in addition to a primary disease of interest. The extent to which co-morbidity affects how well treatments are tolerated will necessarily relate to the type and severity of co-morbidity and the specific treatment. For example, patients with severe chronic airways disease are unlikely to tolerate pneumonectomy for lung cancer, but may tolerate treatment that does not affect the lung and patients with severe renal impairment are unlikely to tolerate nephrotoxic chemotherapy but may tolerate other chemotherapy drugs. Several authors have reported that co-morbidity does not increase the frequency or severity of treatment complications in some circumstances $[9,10]$. In contrast, other studies have reported higher rates of complications among cancer patients with co-morbidity [11,12]. An important factor that impacts on the cancer treatment uptake and completion is interaction with other drugs. Those with co-morbidity are likely to be on several prescribed, over-the-counter, or alternative medications, which can interact with each other and with chemotherapeutic agents, potentially leading to increased toxicity, reduction in the effectiveness of a therapeutic regime, or reduction in compliance $[13,14]$.

The occurrence of anxiety and depression worsen the cancer condition which leads to delay in treatment outcome. In an experimental study, there is evidence that psychological stress (anxiety and depression) can affect a tumour's ability to grow and spread. This psychological stress is associated with higher rates of death, although the mechanism for this outcome is unclear. It may be that people who feel helpless or hopeless do not seek treatment when they become ill, give up prematurely on or fail to adhere to potentially helpful therapy, engage in risky behaviours such as drug use, or do not maintain a healthy lifestyle, resulting in premature death. So, due to increased growth and spread of tumour and fail to adhere to potentially helpful therapy, there will be delayed treatment outcome [15]. Planned teaching programme will be effective in improving knowledge of patients about the effect of risk factors. The importance of planned teaching programme was reported in a study [16]. Apart from these factors, lifestyle and diet al. so plays an important role in effectiveness of therapy. It was reported that smokers and non-vegetarians are more prone to oral cancer [17].

\section{CONCLUSION}

Usually age of the cancer patient has an inverse relationship with the effectiveness of chemotherapy treatment. As the age of the patient increases, the physiological functioning decreases, this in turn affects the pharmacokinetic pattern of drugs and thus pharmacodynamics too. However, age as a risk factor cannot be managed. Physical functioning has an impact on treatment outcome. If the physical functioning deteriorates, then the treatment was stopped till the physical functioning regains to tolerate the treatment which leads to delay in chemotherapy treatment and show impact on treatment outcome. Physical functioning can be assessed using Karnofsky performance status scale, Eastern Cooperative Oncology Group scale, Barthel index. The effect of comorbidity on the effectiveness of chemotherapy depends on the type and severity of comorbidity. There is a dilemma regarding the effect of comorbidity on the overall survival and its effect on the treatment outcome. Anxiety and depression itself worsens the cancer condition by affecting the tumors ability to grow and spread. Adverse drug reactions are inevitable. They result in dose alterations or temporary cessation of the treatment, which altogether results in disease progression. In the present study, statistically significant association between age, physical functioning, co-morbidities, anxiety and depression and effectiveness of chemotherapy treatment was observed. So, by predicting these risk factors prior to the initiation of treatment, we can minimize their unfavourable effect on the effectiveness of treatment.

\section{AUTHOR CONTRIBUTION}

Vinodkumar Mugada-concept, design, literature search, manuscript preparation, editing and review

Pidaparthy Prashanth-concept, design, definition of intellectual content

Polaramsetti Snehapriyanka-concept, data acquisition, data analysis, statistical analysis

Pedasanaganti Jyothirmai-data acquisition, data analysis, statistical analysis

\section{LIMITATION}

The sample size was relatively small due to short duration of the study. Similar studies with good sample size are required to draw a proper conclusion.

\section{ABBREVIATION}

CIRS-Cumulative Illness Rating Scale, HADS-Hospital Anxiety and Depression Scale, MSSSS-Medical Social Support Survey Scale, RECIST-Response Evaluation Criteria In Solid Tumours. 


\section{CONFLICTS OF INTERESTS}

All authors have none to declare

\section{REFERENCES}

1. Nature.com: Cancer. Available from: http://http:// www.nature.com/subjects/cancer/. [Last accessed on 20 May 2017]

2. Roeland EJ, LeBlanc TW. Palliative chemotherapy: oxymoron or misunderstanding? BMC Palliative Care 2016;15:33.

3. Lyman GH, Kuderer NM. Epidemiology of febrile neutropenia. Support Cancer Ther 2003;1:23-35.

4. Lyman GH, Morrison VA, Dale DC, Crawford J, Delgado DJ, Fridman M. OPPS working group; ANC Study Group. Risk of febrile neutropenia among patients with intermediate-grade non-Hodgkin's lymphoma receiving CHOP chemotherapy. Leuk Lymphoma 2003;44:2069-76.

5. Tan M. Social support and coping in Turkish patients with cancer. Cancer Nurs 2007;30:498-504.

6. Due P, Holstein B, Lund R, Modvig J, Avlund K. Social relations: network, support and relational strain. Soc Sci Med 1999;48:661-73.

7. Jones RA, Taylor AG, Bourguignon C, Steeves R, Fraser G, Lippert $\mathrm{M}$, et al. Family interactions among African American prostate cancer survivors. Family Community Health 2008;31:213-20.

8. Ardith D, Barbara G, Charles G, Natalya V. Physical functioning: effect of behavioral intervention for symptoms among individuals with cancer. Nurs Res 2006;55:161-71.

9. Meyerhardt JA, Catalano PJ, Haller DG, Mayer RJ, Macdonald JS, Benson AB. 3rd. Fuchs CS. Impact of diabetes mellitus on outcomes in patients with colon cancer. J Clin Oncol 2003;21:433-40.
10. Gross CP, McAvay GJ, Guo Z, Tinetti ME. The impact of chronic illnesses on the use and effectiveness of adjuvant chemotherapy for colon cancer. Cancer 2007;109:2410-9.

11. Sarfati D, Tan L, Blakely T, Pearce N. Comorbidity among patients with colon cancer in New Zealand. N Z Med J 2011;124:76-88.

12. Lee L, Cheung WY, Atkinson E, Krzyzanowska MK. Impact of comorbidity on chemotherapy use and outcomes in solid tumors: a systematic review. J Clin Oncol 2011;29:106-17.

13. Riechelmann RP, Del Giglio A. Drug interactions in oncology: how common are they? Ann Oncol 2009;20:1907-12.

14. Blower P, de Wit R, Goodin S, Aapro M. Drug-drug interactions in oncology: why are they important and can they be minimized? Crit Rev Oncol Hematol 2005;55:117-42.

15. Cancer. gov: Psychological Stress and Cancer. Available from: https://www.cancer.gov/aboutcancer/coping/feelings/stress-fact-sheet. [Last accessed on 20 May 2017]

16. Prakash MN, Vaishali RM, Anagha VK, Prabhuswami H, Mahesh C. Effectiveness of planned teaching programme on knowledge regarding cervical cancer among women. Asian J Pharm Clin Res 2017;10:335-8.

17. Aiswarya Purushothaman, Roshni PR. A retrospective study on etiological factors, patient characterstics and prescription pattern of oral carcinoma in a tertiary care hospital. Asian J Pharm Clin Res 2015;8:160-2.

\section{How to cite this article}

- Vinodkumar Mugada, Polaramsetti Sneha Priyanka, Pidaparthy Prashanth, Pedasanaganti Jyothirmai. Association of patient related riskfactors with effectiveness of palliative chemotherapy in cancer patients. Int J Pharm Pharm Sci 2017;9(10):160-164. 